\title{
Effect of heat treatments on stability of $\beta$-lactams in milk
}

\author{
M. Roca, ${ }^{*}$ L. Villegas, $†$ M. L. Kortabitarte, $†$ R. L. Althaus, $\neq$ and M. P. Molina*1 \\ *Instituto de Ciencia y Tecnología Animal, Universidad Politécnica de Valencia, Camino de Vera 14, Apartado 46022 Valencia, Spain \\ †Instituto Lactológico de Lekunberri, Departamento de Investigación y Desarrollo, Plazaola 23, Apartado 31870 Lekunberri, Navarra, Spain \\ ‡Departamento de Ciencias Básicas, Facultad de Agronomía y Veterinaria, Universidad Nacional del Litoral, R.P.L. Kreder 2805, \\ 3080 Esperanza, Argentina
}

\section{ABSTRACT}

The presence of residues of antimicrobial substances in milk may have serious toxicological and technical consequences. To date, few studies have been done to evaluate the effect of heat treatments on $\beta$-lactam residues in milk. However, the few studies that have been conducted estimate losses of antimicrobial activity under different combinations of temperature and time using microbiological methods. The aims of this study were to calculate the kinetic parameters for the degradation of $\beta$-lactam antibiotics in milk and to develop prediction models to estimate the concentration losses of these compounds in conventional dairy heat treatments. To do so, we employed a quantitative HPLC method to calculate losses in concentrations of $10 \beta$-lactam antibiotics in milk with different combinations of temperature and time. Increasing the temperature from $60^{\circ} \mathrm{C}$ to $100^{\circ} \mathrm{C}$ decreased the half-life of amoxicillin (372 to $50 \mathrm{~min}$ ), ampicillin (741 to $26 \mathrm{~min}$ ), cloxacillin (367 to $46 \mathrm{~min}$ ), and penicillin G (382 to 43 min). These increases in temperature caused further degradation in cephalosporins, which was accompanied by a decrease in half-life times to reach very low values; for instance, 4, 5, and 6 min for cefoperazone, cephurexime, and cephapirin, respectively. Kinetic equations were applied to different heat treatments used in dairy processing. Heat treatments at high temperatures and long times (e.g., $120^{\circ} \mathrm{C}$ for $20 \mathrm{~min}$ ) led to a further degradation of $\beta$-lactam antibiotics with percentages close to $100 \%$ for cefoperazone and cefuroxime. In contrast, when milk was subjected to heat treatments at lower temperatures and times (e.g., $72^{\circ} \mathrm{C}$ for $15 \mathrm{~s}$ ), the degradation of $\beta$-lactam in milk did not exceed $1 \%$ for the 10 antibiotics tested.

Key words: antibiotics, milk, $\beta$-lactams, thermostability

Received July 6, 2010.

Accepted November 11, 2010.

${ }^{1}$ Corresponding author: pmolina@dca.upv.es

\section{INTRODUCTION}

$\beta$-Lactam antibiotics (penicillins and cephalosporins) are antimicrobial drugs widely used in veterinary medicine for preventing and treating mastitis and other bacterial infections in dairy cattle (Honkanen-Buzalski and Reybroeck, 1997; Botsoglou and Fletouris, 2001; Bradley and Green, 2009). Improper use of $\beta$-lactam antibiotics may lead to residues in milk, especially when withdrawal times are not respected (Pengov, 2009). These residues can be toxic and dangerous for human health, and may cause allergic reactions and antimicrobial resistance (Guillemot et al., 1998; Wilke et al., 2005). They may also represent a technological problem for industry production affecting bacterial fermentation processes in dairy products such as yogurt and cheese (Packham et al., 2001; Demoly and Romano, 2005). Consequently, Codex Alimentarius (2009) has established safe levels of antimicrobials in edible tissues. Furthermore, the European Union has regulated the maximum residue limits allowed in milk and other animal foodstuffs by means of Council Regulation 37/2010/EC (European Council, 2010).

$\beta$-Lactam residues that may appear in milk are molecules in solution of the pharmaceutical active ingredients of drugs in use. These compounds can, therefore, degrade depending on the different factors that normally affect their stability. Temperature is one of the most important of these factors because it can lead to changes in the decomposition of the molecules in such solutions (Connors et al., 1994; Carstensen and Rhodes, 2000). The degradation kinetics of a chemical reaction as a result of temperature is defined by the Arrhenius equation (Ash and Ash, 1995), which relates the degradation reaction rate to increasing temperature. Moreover, the order of the reaction establishes a relationship between the concentration and degradation rate of each compound (Martin, 1993). From these kinetics, parameter-based prediction models can be developed to estimate the concentration losses of antimicrobial compounds in terms of temperature and time.

The degradation mechanisms of $\beta$-lactam antibiotics have been widely studied from a pharmaceutical 
viewpoint, in aqueous solutions, at different $\mathrm{pH}$, under different storage conditions, in the presence of metal ions, and so on (Zajac et al., 1998; Akaho and Nakayama, 2003; Miller et al., 2004). However, very few studies have investigated the effects of temperature on these compounds in foodstuffs (Moats, 1988, 1999; Zorraquino et al., 2008).

Should milk reach the dairy industry with $\beta$-lactam antibiotic residues, the residues may degrade during the pasteurization and sterilization treatments that milk undergoes to ensure its quality and conservation. The relevance of possible heat-inactivation of $\beta$-lactam residues in milk for food safety indicates the need to define the effects of heat on these compounds.

Moats (1988, 1999) and Zorraquino et al. (2008) indicated that molecules of $\beta$-lactam antibiotics undergo loss of antimicrobial activity when milk samples are subjected to heat treatments at fixed times and temperatures. These losses can be quantified by microbiological bioassays. Unfortunately, predictive kinetic models cannot be applied to the procedures described in these studies to estimate the thermal degradation of $\beta$-lactam antibiotics for different heat treatments because the previous studies calculated only the percentage loss of antimicrobial activity.

To carry out kinetic studies on the degradation of antibiotics, Roca et al. (2010) analyzed the thermal degradation of quinolones in milk treated at different temperatures and times using a liquid chromatography method with a fluorescence detector.

Currently, the on-line combination of liquid chromatography with different detectors has led to the development of a widely applicable detection and quantification system for $\beta$-lactam residue analysis in different animal food products, including milk (Tarbin et al., 1995; Holstege et al., 2002; Ghidini et al., 2003). These methods are capable of detecting relatively small amounts of a target compound, thereby enhancing sensitivity, which proves a useful methodology for thermal degradation studies.

Therefore, the aims of this study were to analyze the effect of the temperatures and times of heat treatments on the concentration of $10 \beta$-lactam antibiotics (penicillins and cephalosporins) in milk using an HPLC method to determine degradation kinetic models and to subsequently calculate losses of concentration through conventional milk processing.

\section{MATERIALS AND METHODS}

\section{Reagents and Standards}

Amoxicillin, ampicillin, cloxacillin sodium salt, penicillin G sodium salt, cephalexin, cephalonium, cefop- erazone, cephapirin sodium salt, and cephuroxime were purchased from Sigma Chemical Co. (St. Louis, MO). Cefquinome was supplied by Intervet (Unterschelßheim, Germany). Stock dissolutions of standards were prepared in water at $1 \mathrm{mg} / \mathrm{mL}$ after correcting for purity. Cephalonium was dissolved in acetonitrile-water (50:50, $\mathrm{vol} / \mathrm{vol}$ ). Solutions were prepared daily and stored at $4^{\circ} \mathrm{C}$ until spiked samples were prepared. All organic reagents and other materials were of the highest purity or of HPLC grade (Sigma Chemical Co.). The water used was obtained from a Milli-Q system (Millipore Corp., Bedford, MA).

\section{Spiked Milk Samples and Heat Treatments}

Spiked samples were prepared by fortifying skim milk powder for microbiology purposes (ref. 115363, Merck, Darmstadt, Germany), which was reconstituted to $10 \%$ with solutions of stock $\beta$-lactam solution to obtain samples with $5,000 \mu \mathrm{g} / \mathrm{kg}$. Samples were then divided into aliquots to study the effect of different temperatures $\left(60,70,80,90\right.$, and $\left.100^{\circ} \mathrm{C}\right)$ during incubation in a thermostatic water bath at different times. Table 1 provides the heat treatments used in this study.

\section{Extraction Procedure}

The analytical techniques, described as follows, were carried out in accordance with the protocols established and validated at the Instituto Lactológico de Lekunberri (Lekunberri, Pamplona), using ISO standard 17025 (ISO/IEC, 2005) and the method described by Moats and Harik-Khan (1995).

For the extraction procedure, $10 \mathrm{~g}$ of spiked milk was weighed into a $125-\mathrm{mL}$ flask and $2 \mathrm{~mL}$ of $0.2 \mathrm{M}$ tetraethyl ammonium chloride solution was added. Then, $38 \mathrm{~mL}$ of acetonitrile was incorporated slowly with a burette to achieve deproteinization of milk while continuously stirring the flask to avoid variation in recoveries (Moats and Malisch, 1992). After $10 \mathrm{~min}$, the supernatant liquid was decanted and filtered to a side-arm flask through a funnel with glass wool. Then, $1 \mathrm{~mL}$ of water was added and the flask was placed in a thermostatic bath at $45^{\circ} \mathrm{C}$, which was connected to a vacuum to evaporate the collected solution under reduced water pressure after initially boiling to dryness. The residue was reconstituted with $4 \mathrm{~mL}$ of water. The solution was mixed using a vortex mixer, homogenized in the ultrasonic bath, filtered into a chromatographic vial using a $0.45-\mu \mathrm{m}$ polyvinylidene fluoride filter, and introduced into the chromatographic clean-up system. Antibiotics eluted at different retention times and were collected in different fractions for the analysis. 
Table 1. Heat treatments (temperature and time combinations) used to study the degradation of $\beta$-lactams

\begin{tabular}{lcl}
\hline$\beta$-lactam & Temperature $\left({ }^{\circ} \mathrm{C}\right)$ & Time $(\mathrm{min})$ \\
\hline Penicillins & & \\
Amoxicillin & 60 & $0,60,120,180,240,300,360$ \\
Ampicillin & 70 & $0,60,120,180,240,300,360$ \\
Cloxacillin & 80 & $0,60,120,180,240,300,360$ \\
Penicillin G & 90 & $0,30,60,90,120,150,180$ \\
Cephalosporins & & \\
Cefoperazone & 60 & $0,30,60,90,120,150,180$ \\
Cefquinome & 70 & $0,30,60,90,120,150,180$ \\
Cephalexin & 80 & $0,15,30,90,120,150,180$ \\
Cephapirin & 90 & $0,15,30,45,60,75,90$ \\
Cephalonium & 100 & $0,30,60,90,120,150,180$ \\
Cephuroxime & 60 &
\end{tabular}

\section{Chromatographic Determination}

The procedure used for the determination of penicillins and cephalosporins was essentially the same. The spiked milk concentrations for cephalosporins were higher than those for penicillins, and the compounds were identified and directly quantified in the chromatographic clean-up system. Penicillins were first separated with the chromatographic clean-up system and then quantified with a second chromatographic analysis.

Chromatographic Separation (Clean-Up). The separation and measurement of compounds were conducted by employing a liquid chromatography equipment clean-up system with a Waters 600 Controller 4-channel delivery solvent pump and a Waters 717 Plus automatic injector, a Waters $486 \mathrm{UV}-\mathrm{Vis}$ detector and a Waters fraction collector (Waters Chromatography Division, Milford, MA). Chromatographic system operation and data collection were controlled by the Empower Pro Millenium 40 software (Waters Chromatography Division).

The mobile phase consisted of A (0.01 $M$ solution of potassium phosphate monobasic anhydrous solution) and $\mathrm{B}$ (acetonitrile). The solvent gradient conditions of the liquid chromatography mobile phase were as follows: time $(t)=0-3 \mathrm{~min}$, hold $100 \% \mathrm{~A}$ and $0 \% \mathrm{~B}$; $t=3-40 \mathrm{~min}, 60 \% \mathrm{~A}$ and $40 \% \mathrm{~B} ; t=40-45 \mathrm{~min}$, $100 \% \mathrm{~A}$ and $0 \% \mathrm{~B}$. The flow rate was $1.0 \mathrm{~mL} / \mathrm{min}$ and the sample injection volume was 1,000 $\mu \mathrm{L}$. Compound separation was carried out using a $\mathrm{C}_{18}$ column (Waters Chromatography Division) and the UV detector was set at $210 \mathrm{~nm}$. The collector was programmed to collect those fractions in which the analytes would elute, adjusted to their retention times, to achieve different 5 -min fractions $(\mathbf{F})$ per sample: $\mathrm{F}_{1}(4-9 \mathrm{~min})$ : amoxicillin; $\mathrm{F}_{4}$ (19-24 min): ampicillin; $\mathrm{F}_{6}(28-33 \mathrm{~min})$ : penicillin G; and $\mathrm{F}_{7}(33-38 \mathrm{~min})$ : cloxacillin. Fractions of cephalosporins were collected as $\mathrm{F}_{4}$ and $\mathrm{F}_{5}$ fractions, and the conditions of this chromatographic analysis of- fered high resolution. Therefore, it was not necessary to use another analysis system to quantify the loss in concentration of these substances.

Chromatographic Analysis. Penicillins were analyzed by using a chromatographic system that comprised an Alliance Waters 2695 separation module equipped with a pump and an automatic injector and a Waters 996 photodiode detector (Waters Chromatography Division). The collected penicillin fractions were concentrated to $1 \mathrm{~mL}$ in the evaporator-concentrator at $45^{\circ} \mathrm{C}$. Next, $200 \mu \mathrm{L}$ of each fraction was injected into the chromatographic analysis system. In this case, the chromatographic conditions were the same for all the penicillins, unlike those described by Moats and HarikKhan (1995). The mobile phase used was isocratic and consisted of A (0.0075 M SDS and 0.015 $M$ phosphoric acid) and $\mathrm{B}$ (acetonitrile) at a proportion of 65:35. The flow rate was $1 \mathrm{~mL} / \mathrm{min}$. Separation of compounds was accomplished using a $\mathrm{C}_{18}$ column (Waters Chromatography Division) and the detector scanned continuously in the 200 to $400 \mathrm{~nm}$ range.

\section{Statistical Analysis}

The adjusted kinetic first-order model (Martin, 1993), based on the decreasing availability of the target compound, was developed to fit the thermal degradation of $\beta$-lactams as follows:

$$
\frac{\partial[C]}{\partial t}=-k_{1} \cdot[C]
$$

where $\frac{\partial[C]}{\partial t}$ is derived from the $\beta$-lactam concentration in relation to time $t, k_{1}$ is the degradation rate constant, and $[C]$ is the concentration of each compound in the milk sample at different times. By integrating equation [1], we obtain 
Table 2. Parameters of the first-order degradation kinetic model of penicillins in milk at different temperatures

\begin{tabular}{|c|c|c|c|c|c|c|}
\hline Temperature $\left({ }^{\circ} \mathrm{C}\right)$ & Intercept (a) & Slope $\left(k_{1}\right)$ & \multicolumn{2}{|c|}{ Standard error } & $P$-value & $\mathrm{R}^{2}$ \\
\hline \multicolumn{7}{|l|}{ Amoxicillin } \\
\hline $70^{\circ} \mathrm{C}$ & 8.448 & -0.00311 & 0.07500 & 0.00035 & 0.0003 & 0.94 \\
\hline $80^{\circ} \mathrm{C}$ & 8.352 & -0.00539 & 0.13326 & 0.00062 & 0.0003 & 0.94 \\
\hline $90^{\circ} \mathrm{C}$ & 8.378 & -0.00859 & 0.11436 & 0.00100 & 0.0010 & 0.95 \\
\hline $60^{\circ} \mathrm{C}$ & 8.437 & -0.00181 & 0.04080 & 0.00019 & 0.0002 & 0.95 \\
\hline $70^{\circ} \mathrm{C}$ & 8.450 & -0.00395 & 0.08052 & 0.00037 & 0.0001 & 0.96 \\
\hline $80^{\circ} \mathrm{C}$ & 8.506 & -0.00558 & 0.09322 & 0.00043 & 0.0001 & 0.97 \\
\hline $90^{\circ} \mathrm{C}$ & 8.387 & -0.01058 & 0.09322 & 0.00086 & 0.0001 & 0.97 \\
\hline $100^{\circ} \mathrm{C}$ & 8.477 & -0.01506 & 0.16003 & 0.00148 & 0.0002 & 0.95 \\
\hline \multicolumn{7}{|l|}{ Cloxacillin } \\
\hline $60^{\circ} \mathrm{C}$ & 8.437 & -0.00181 & 0.04080 & 0.00019 & 0.0002 & 0.95 \\
\hline $60^{\circ} \mathrm{C}$ & 8.519 & -0.00093 & 0.01583 & 0.00007 & 0.0001 & 0.96 \\
\hline $70^{\circ} \mathrm{C}$ & 8.495 & -0.00154 & 0.02942 & 0.00013 & 0.0003 & 0.94 \\
\hline $80^{\circ} \mathrm{C}$ & 8.654 & -0.00702 & 0.18494 & 0.00085 & 0.0003 & 0.94 \\
\hline $90^{\circ} \mathrm{C}$ & 8.399 & -0.00745 & 0.09058 & 0.00084 & 0.0003 & 0.94 \\
\hline $100^{\circ} \mathrm{C}$ & 8.561 & -0.02627 & 0.06973 & 0.00065 & 0.0001 & 1.00 \\
\hline
\end{tabular}

$$
\ln [C]=\ln \left[C_{0}\right]-k_{1} \cdot t
$$

where $\left[C_{0}\right]$ is the initial concentration of each compound at $t=0$.

To study the variations in antimicrobial concentrates in time, a simple linear regression model was applied following the PROC REG procedure from SAS (SAS Institute, 2001).

For each temperature, half-lives $\left(\mathbf{t}_{1 / 2}\right)$ were calculated as the time ( $\mathrm{min}$ ) required for antimicrobial activity to decrease to half its initial value (Chen et al., 1997), as shown by this equation:

$$
t_{1 / 2}=\frac{\ln 2}{k}
$$

According to the theory postulated by Arrhenius (Ash and Ash, 1995), degradation rate constants $\left(k_{1}\right)$ depend on temperature and can be expressed as

$$
k=A \cdot e^{-\frac{E a}{R \cdot T}}
$$

where $A$ is the frequency factor, $e$ is the base of the natural logarithms $(\mathrm{e}=2.7182), E a$ is the activation energy, $R$ is the universal gas constant $(R=8.315 \mathrm{~J} /$ mol K), and $T$ is the absolute temperature $(\mathrm{K})$. By logarithmically transforming equation [4], the following equation is obtained:

$$
\ln k=\ln A-\frac{E a}{R \cdot T}
$$

The application of the linear regression model to the logarithmic transformations of the degradation rate constant based on the inverse values of the absolute temperatures allows the $\ln A$ and $E a$ values to be calculated. To do this, the PROC REG procedure of SAS (SAS Institute, 2001) was used.

Finally, by using equations [2] and [5], we can estimate the degradation percentages of each $\beta$-lactam for all the different heat treatments, as shown in equation [6]:

Degradation $(\%)=\frac{C_{0}-C}{C_{0}} \times 100=\left(1-e^{\left[A \cdot e^{\left(-\frac{E a}{R \cdot T}\right)}\right] \cdot t}\right) \times 100$.

\section{RESULTS AND DISCUSSION}

Tables 2 and 3 show the simple linear regression equations obtained from the logarithmic transformations of the concentrations of both penicillins and 
Table 3. Parameters of the first-order degradation kinetic model of cephalosporins in milk at different temperatures

\begin{tabular}{|c|c|c|c|c|c|c|}
\hline Temperature $\left({ }^{\circ} \mathrm{C}\right)$ & Intercept (a) & Slope $\left(k_{1}\right)$ & \multicolumn{2}{|c|}{ Standard error } & $P$-value & $\mathrm{R}^{2}$ \\
\hline \multicolumn{7}{|l|}{ Cefoperazone } \\
\hline $70^{\circ} \mathrm{C}$ & 8.520 & -0.01261 & 0.04132 & 0.00115 & 0.0001 & 0.96 \\
\hline $80^{\circ} \mathrm{C}$ & 8.373 & -0.01729 & 0.06738 & 0.00187 & 0.0002 & 0.94 \\
\hline $90^{\circ} \mathrm{C}$ & 8.219 & -0.12542 & 0.13166 & 0.00730 & 0.0001 & 0.98 \\
\hline \multicolumn{7}{|l|}{ Cefquinome } \\
\hline $60^{\circ} \mathrm{C}$ & 8.523 & -0.00688 & 0.01799 & 0.00050 & 0.0001 & 0.97 \\
\hline $70^{\circ} \mathrm{C}$ & 8.492 & -0.00772 & 0.03037 & 0.00084 & 0.0003 & 0.94 \\
\hline $80^{\circ} \mathrm{C}$ & 8.464 & -0.00813 & 0.03268 & 0.00090 & 0.0003 & 0.94 \\
\hline $90^{\circ} \mathrm{C}$ & 8.415 & -0.02329 & 0.04901 & 0.00272 & 0.0004 & 0.94 \\
\hline $100^{\circ} \mathrm{C}$ & 8.504 & -0.04677 & 0.04032 & 0.00224 & 0.0001 & 0.99 \\
\hline \multicolumn{7}{|l|}{ Cephalexin } \\
\hline $60^{\circ} \mathrm{C}$ & 8.492 & -0.00601 & 0.02559 & 0.00071 & 0.0004 & 0.93 \\
\hline $60^{\circ} \mathrm{C}$ & 8.545 & -0.00545 & 0.02093 & 0.00058 & 0.0002 & 0.95 \\
\hline $70^{\circ} \mathrm{C}$ & 8.462 & -0.01063 & 0.03147 & 0.00087 & 0.0001 & 0.97 \\
\hline $80^{\circ} \mathrm{C}$ & 8.462 & -0.01441 & 0.03683 & 0.00102 & 0.0001 & 0.98 \\
\hline $90^{\circ} \mathrm{C}$ & 8.462 & -0.02934 & 0.03862 & 0.00214 & 0.0001 & 0.97 \\
\hline $100^{\circ} \mathrm{C}$ & 8.512 & -0.05142 & 0.03076 & 0.00171 & 0.0001 & 0.99 \\
\hline \multicolumn{7}{|l|}{ Cephapirin } \\
\hline $60^{\circ} \mathrm{C}$ & 8.445 & -0.01734 & 0.06489 & 0.00180 & 0.0002 & 0.95 \\
\hline $70^{\circ} \mathrm{C}$ & 8.345 & -0.02189 & 0.08313 & 0.00231 & 0.0002 & 0.95 \\
\hline $80^{\circ} \mathrm{C}$ & 8.308 & -0.03865 & 0.15677 & 0.00435 & 0.0003 & 0.94 \\
\hline $90^{\circ} \mathrm{C}$ & 8.282 & -0.14753 & 0.14753 & 0.00818 & 0.0002 & 0.95 \\
\hline $100^{\circ} \mathrm{C}$ & 8.262 & -0.11303 & 0.18419 & 0.01022 & 0.0001 & 0.96 \\
\hline \multicolumn{7}{|l|}{ Cephuroxime } \\
\hline $60^{\circ} \mathrm{C}$ & 8.557 & -0.00786 & 0.03232 & 0.00090 & 0.0003 & 0.94 \\
\hline $70^{\circ} \mathrm{C}$ & 8.528 & -0.01276 & 0.04518 & 0.00125 & 0.0002 & 0.95 \\
\hline
\end{tabular}

cephalosporins in milk according to the different heat treatment times. In all cases, the quadratic regression coefficients $\left(\mathrm{R}^{2}\right)$ were high, indicating that the kinetic model was valid to study the thermal degradation of $\beta$-lactam antibiotics in milk. It is also noteworthy (Tables 2 and 3 ) that the effect of heat treatment time on the thermal degradation of $\beta$-lactams was highly significant in all cases $(P<0.001)$, and the term of the slope increased for higher temperatures for all of the $\beta$-lactam antibiotics.

Figures 1 and 2 illustrate the thermal degradation of $\beta$-lactam antibiotics in milk and the lines calculated by the regression model for the different treatments studied. Greater thermal degradation of $\beta$-lactams can be observed when heating time was prolonged and temperature increased.

Degradation of $\beta$-lactams has been studied in the presence of various metal ions to show that these ions catalyze the inactivation of the hydrolytic opening of $\beta$-lactams (Navarro et al., 2003; Michnik et al., 2004;
Alekseev et al., 2006). However, very few studies have been conducted on the chemical and biological degradation of these compounds caused by high temperatures.

The properties of $\beta$-lactams could be explained by the fusion of the $\beta$-lactam ring with the tiazolidine ring, which leads to nonplanarity of molecules, resulting in wide-angled and torsional rotation (Cohen, 1983). This labile molecular structure is characterized by high susceptibility to various nucleophiles, acid and base reagents, metal ions, oxidizing agents, and even solvents like water (Deshpande et al., 2004). Therefore, the degradation of $\beta$-lactams observed in this study could be partly accounted for by the high water content of milk (80\%).

Table 4 shows the half-lives of $\beta$-lactam antibiotics in milk estimated with the first-order kinetic equations for the 5 temperatures assessed. This table also presents the kinetic parameters activation energy (Ea) and collision frequency $(\mathrm{LnA})$ of each substance, which were calculated using the Arrhenius equation (Eq. [4]). 
a) Penicillin

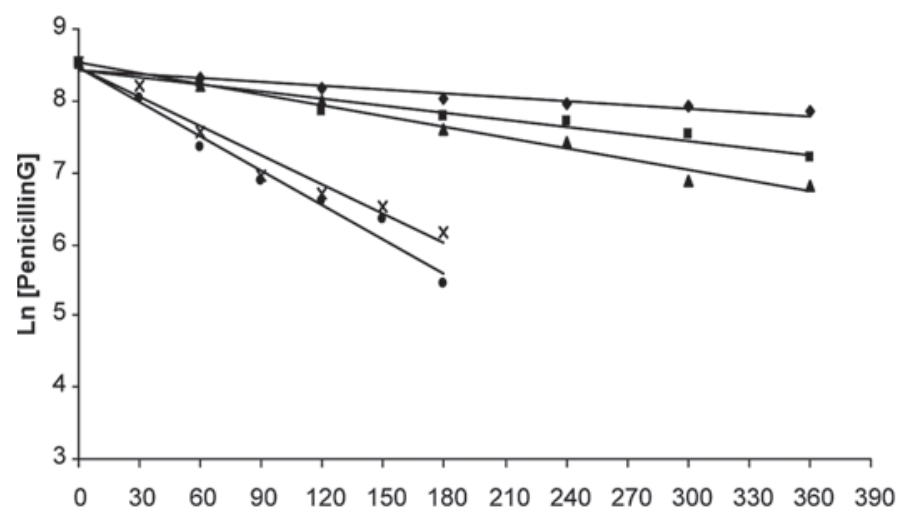

c) Cloxacillin

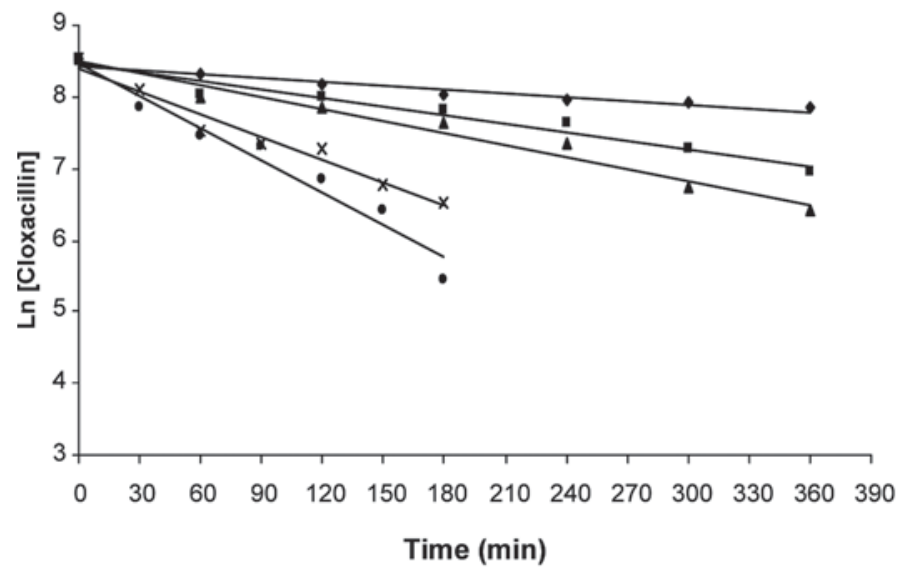

b) Ampicillin

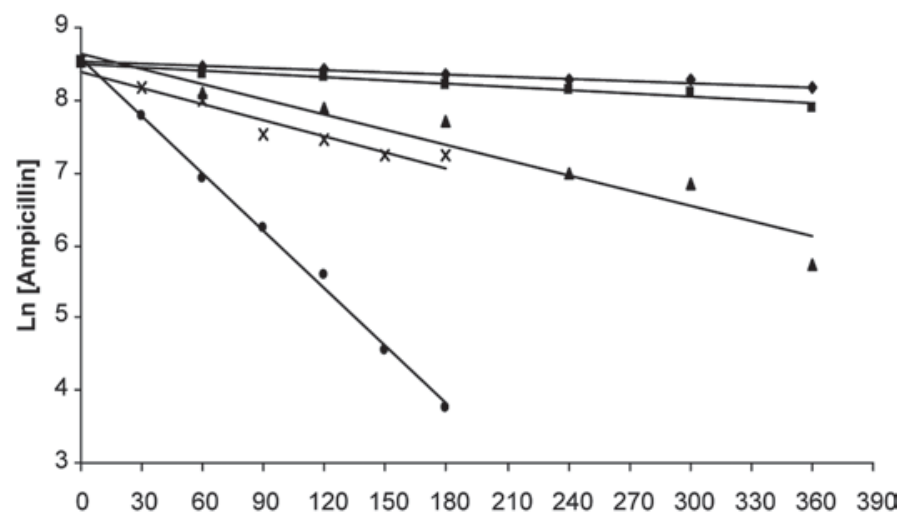

d) Amoxicillin

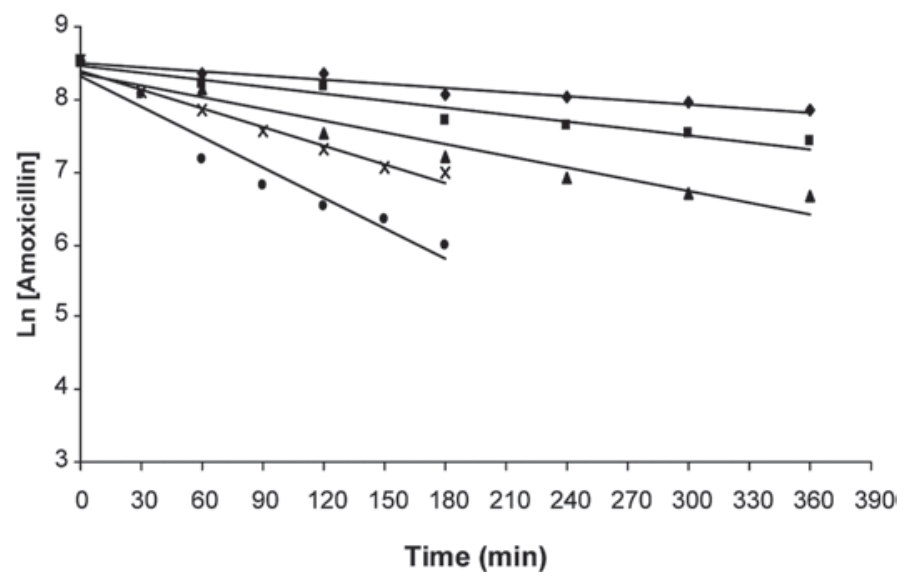

Figure 1. Decreased concentration of penicillins in milk at different heating times and temperatures.

Greater half-lives (Table 4) were found for penicillins than for cephalosporins, indicating the greater thermal instability of cephalosporins, especially cephapirin, cefoperazone, and cephuroxime, with shorter half-lives at $100^{\circ} \mathrm{C}(6,4$, and $5 \mathrm{~min}$, respectively).

The different stability behavior of each antibiotic on the different temperatures tested can be explained by the kinetic parameters LnA and Ea obtained by applying the Arrhenius equation. High Ea indicates that a longer time is needed to reach the activation state of molecules, hence degradation. In addition, the collision frequency number suggests a higher probability of conducting effective shock between molecules, thus accelerating the degradation reaction rate once the molecule reaches the Ea point.

In the literature consulted, Ea values were found only for penicillin $(84.5 \mathrm{~kJ} / \mathrm{mol}$; Pawelczyk et al., 1980) and cloxacillin $(98 \mathrm{~kJ} / \mathrm{mol}$; Rodante et al., 2002) when heat- ing the solid compounds containing these antibiotics. However, the results obtained by these authors differ from our results because of the different analytical and statistical methodologies, foodstuffs, temperature ranges, and kinetic parameters employed.

The Ea values obtained in this study for penicillins and cephalosporins are generally higher than those obtained in the study of heat stability of quinolones in milk (Roca et al., 2010), with values ranging between $27.90 \mathrm{~kJ} / \mathrm{mol}$ (flumequine) and $58.21 \mathrm{~kJ} / \mathrm{mol}$ (ciprofloxacin). Moreover, the collision frequency values for $\beta$-lactam antibiotics were higher than those obtained for quinolones, which had very low values (2.06 and 12.88 for ciprofloxacin and flumequine, respectively). Combining higher Ea and LnA parameters for $\beta$-lactam antibiotics enables them to degrade more rapidly at higher temperatures than quinolones. Once again, this increased degradation of $\beta$-lactams could be explained 
$\cdot 60^{\circ} \mathrm{C}=70^{\circ} \mathrm{C} \wedge 80^{\circ} \mathrm{C} \times 90^{\circ} \mathrm{C} \cdot 100^{\circ} \mathrm{C}$

\section{a) Cephalexin}

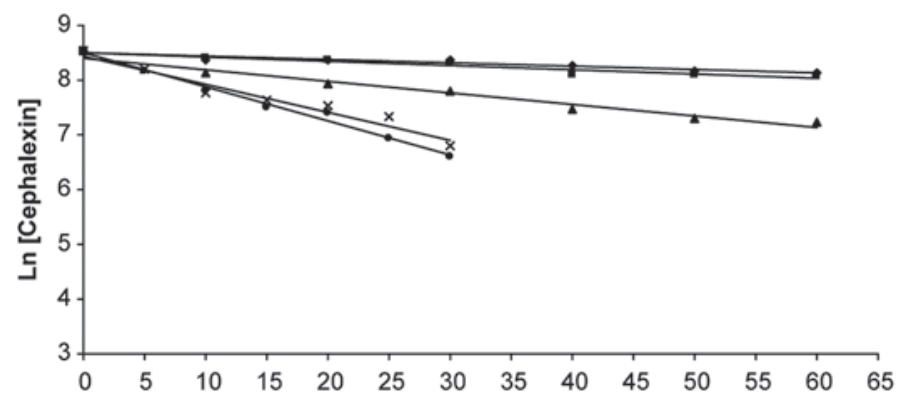

c) Cephapirin

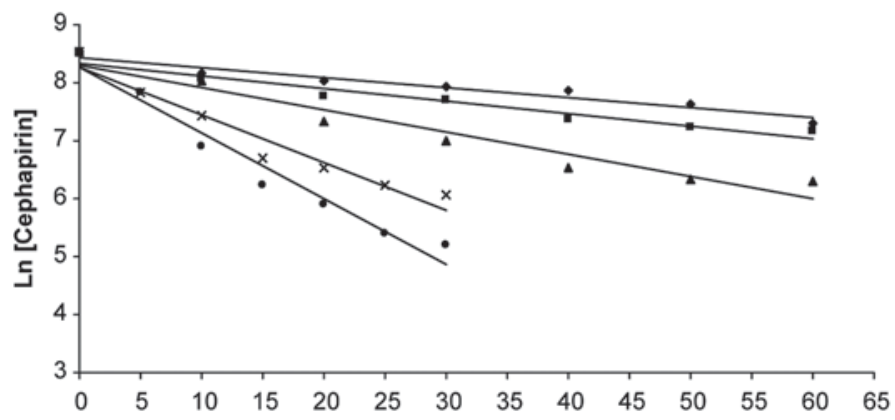

e) Cefquinome

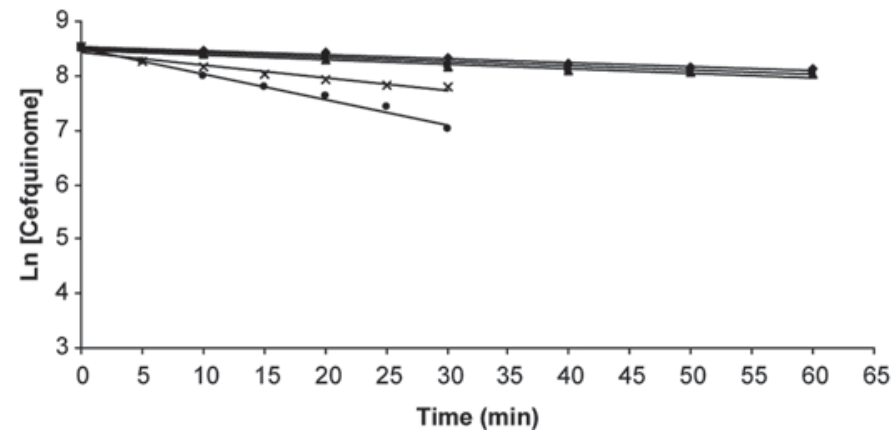

b) Cephalonium

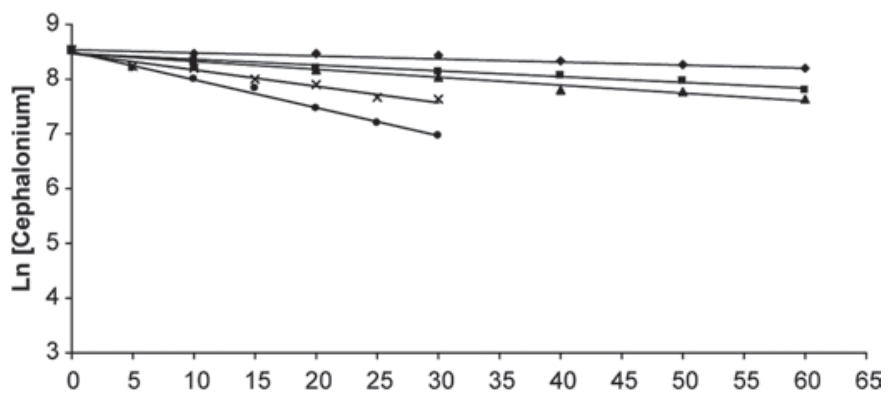

d) Cefoperazone

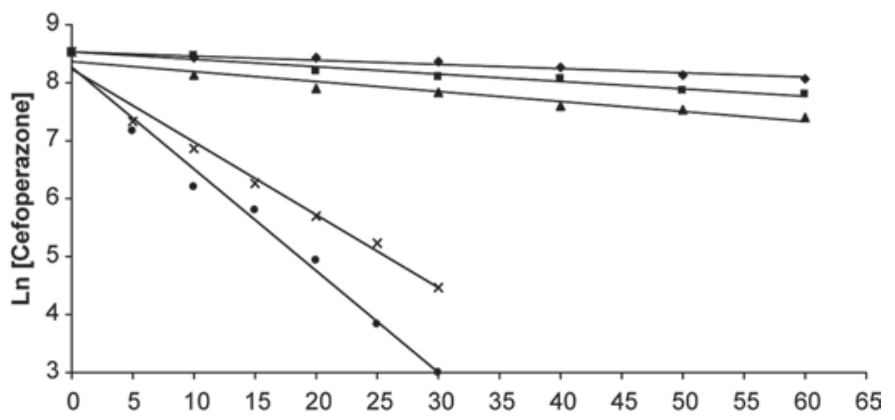

f) Cephuroxime

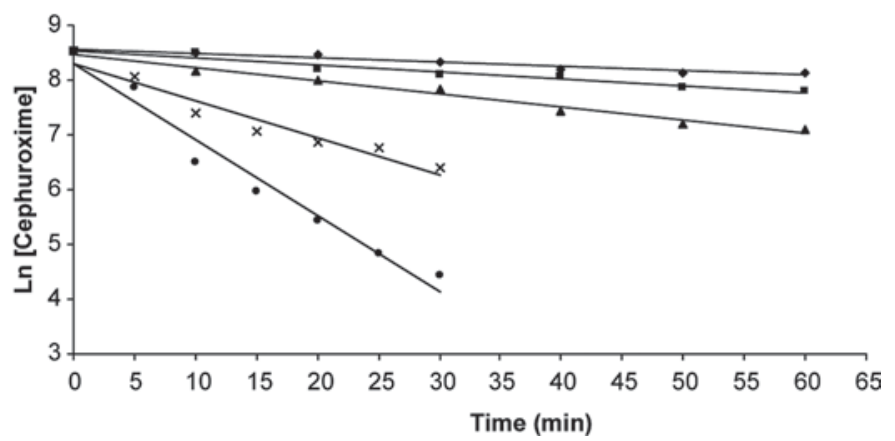

Figure 2. Decreased concentration of cephalosporins in milk at different heating times and temperatures.

by their labile $\beta$-lactam ring if quinolone molecules (the 4-oxo-1,4-dihydro quinoline ring) are compared with covalent bonds that are more stable and more difficult to break.

When applying equation [6], the degradation percentages of each $\beta$-lactam for the different conventional dairy heat treatments were estimated (pasteurization: low-temperature, long-time at $63^{\circ} \mathrm{C}$ for $30 \mathrm{~min}$; HTST at $72^{\circ} \mathrm{C}$ for $15 \mathrm{~s}$; sterilization: $120^{\circ} \mathrm{C}$ for $20 \mathrm{~min}$; and UHT at $140^{\circ} \mathrm{C}$ for $4 \mathrm{~s}$ ). The thermal degradation percentages (Figures 3 and 4) indicated that HTST pasteurization $\left(72^{\circ} \mathrm{C}\right.$ for $\left.15 \mathrm{~s}\right)$ did not cause significant decreases in the levels of the substances tested. On the other hand, low-temperature, long-time pasteurization brought about losses in cephalosporins that reached 22.1 and $42.1 \%$ in cefuroxime and cephapirin, respectively. In line with this, it should be mentioned that the nature of the chemical elements at C-3 and C-7 of the cephalosporins plays an important role in determining the facility with which the $\beta$-lactam bond is hydrolyzed or broken (Cimarusti, 1984). In regard to cephapirin and cefuroxime, both contain ester bonds, which are unstable in biological media, and this could explain the higher degradation rates noted for these analytes at a low temperature $\left(63^{\circ} \mathrm{C}\right)$ compared with those of other compounds. 


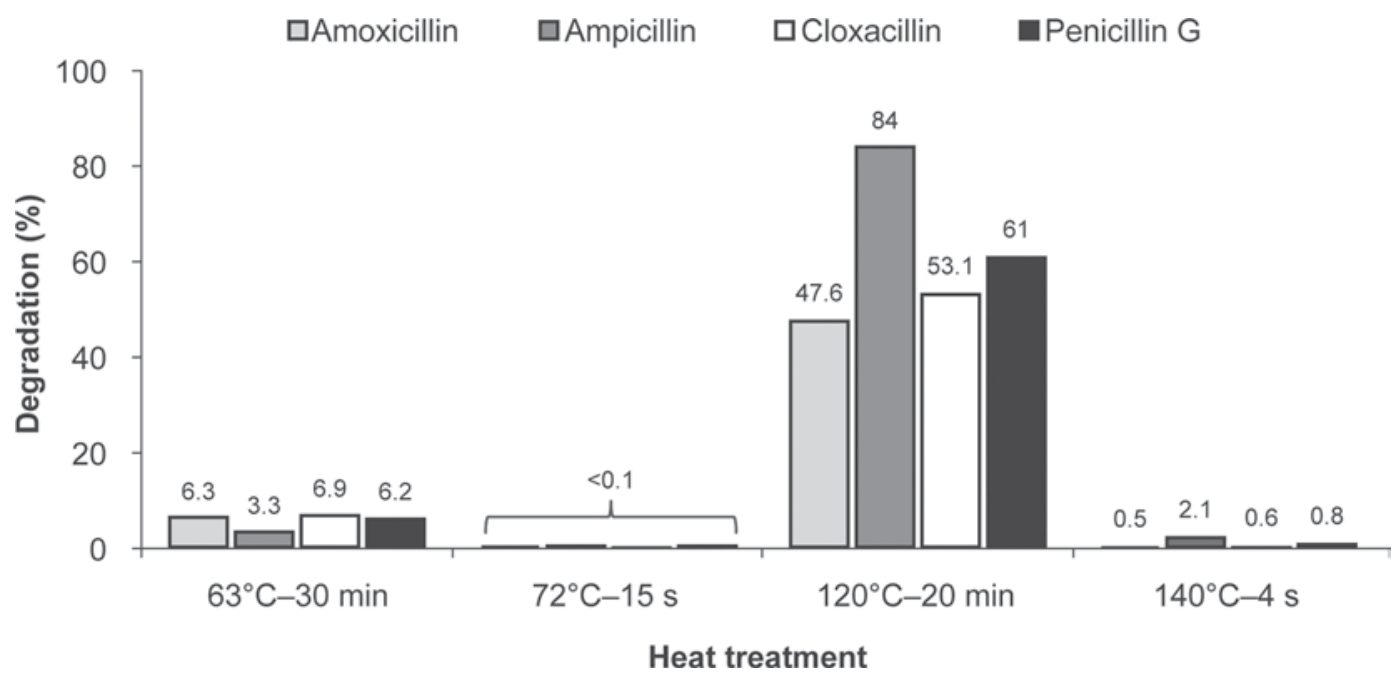

Figure 3. Degradation percentages of penicillins in milk with different heat treatments.

Moreover, in sterilization, the treatment of $120^{\circ} \mathrm{C}$ for 20 min led to high degradation of $\beta$-lactam antibiotics. The degradation rates for penicillin were between $47.6 \%$ (amoxicillin) and 84\% (ampicillin). Cephalosporins had higher degradation rates than penicillins, with higher values in all cases up to $90 \%$, except for cefquinome $(79.9 \%)$, and losses of up to $100 \%$ were observed for cefoperazone and cefuroxime. Furthermore, UHT sterilization $\left(140^{\circ} \mathrm{C}\right.$ for $\left.4 \mathrm{~s}\right)$ led to lower degradation percentages, and the highest values were seen for cefoperazone $(16.8 \%)$ and cefuroxime $(8.6 \%)$.

When comparing the results in Table 4 and Figures 3 and 4 , we see that the lowest half-life values at $100^{\circ} \mathrm{C}$ are for cefoperazone and cefuroxime (4 to $5 \mathrm{~min}$, respectively), which corresponds to the highest degradation rates $(100 \%)$ for the $120^{\circ} \mathrm{C}, 20$-min treatment. The short half-lives and high degradation rates for these compounds also correspond to high kinetic parameter activation energy values (88.84 and $76.22 \mathrm{~kJ} / \mathrm{mol}$, respectively), which afford these molecules very fast degradation at high temperatures.

For penicillins, we find that ampicillin showed shorter half-lives (93 and $26 \mathrm{~min}$ ) at high temperatures (90 and $100^{\circ} \mathrm{C}$, respectively), accompanied by a higher Ea value $(85.09 \mathrm{~kJ} / \mathrm{mol}$, Table 4$)$, thus presenting a high percentage of thermal inactivation for sterilization at $120^{\circ} \mathrm{C}$ for $20 \mathrm{~min}$ (Figure 3 ).

As regards penicillin residues in milk, the literature reviews by Moats $(1988,1999)$ indicated a $59.7 \%$ loss of antimicrobial activity in milk when milk fortified with this antibiotic is heated at $121^{\circ} \mathrm{C}$ for $15 \mathrm{~min}$, which is similar to the result of $61 \%$ thermal degradation estimated in this work for the $120^{\circ} \mathrm{C}, 20$-min heat treatment (Figure 3).

Recently, Zorraquino et al. (2008) calculated antimicrobial activity losses in $\beta$-lactams in milk using a bio-

Table 4. Half-lives $\left(\mathrm{t}_{1 / 2} ; \mathrm{min}\right)$ and kinetic parameters for $\beta$-lactam antibiotics in milk at different temperatures

\begin{tabular}{|c|c|c|c|c|c|c|c|}
\hline \multirow[b]{2}{*}{$\beta$-lactam } & \multicolumn{5}{|c|}{$\mathrm{t}_{1 / 2}$} & \multicolumn{2}{|c|}{ Arrhenius $^{1}$} \\
\hline & $60^{\circ} \mathrm{C}$ & $70^{\circ} \mathrm{C}$ & $80^{\circ} \mathrm{C}$ & $90^{\circ} \mathrm{C}$ & $100^{\circ} \mathrm{C}$ & $\ln \mathrm{A}$ & $\mathrm{Ea}$ \\
\hline \multicolumn{8}{|l|}{ Penicillins } \\
\hline Amoxicillin & 372 & 223 & 129 & 81 & 50 & 12.46 & 51.92 \\
\hline Ampicillin & 741 & 450 & 99 & 93 & 26 & 23.65 & 85.09 \\
\hline Cloxacillin & 367 & 176 & 124 & 66 & 46 & 13.01 & 53.19 \\
\hline Penicillin G & 382 & 213 & 138 & 52 & 43 & 15.18 & 59.61 \\
\hline Cefquinome & 101 & 90 & 85 & 30 & 15 & 12.87 & 50.30 \\
\hline Cephalexin & 115 & 88 & 32 & 14 & 11 & 19.05 & 67.27 \\
\hline Cephalonium & 127 & 65 & 48 & 24 & 13 & 15.23 & 56.64 \\
\hline Cephapirin & 40 & 32 & 18 & 8 & 6 & 14.37 & 52.26 \\
\hline Cephuroxime & 88 & 54 & 29 & 10 & 5 & 22.49 & 76.22 \\
\hline
\end{tabular}

${ }^{1} \mathrm{~A}=$ frequency factor; $\mathrm{Ea}=$ activation energy $(\mathrm{kJ} / \mathrm{mol})$. 


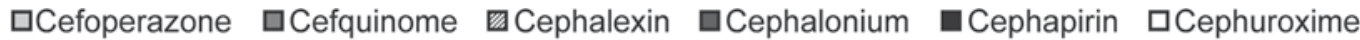

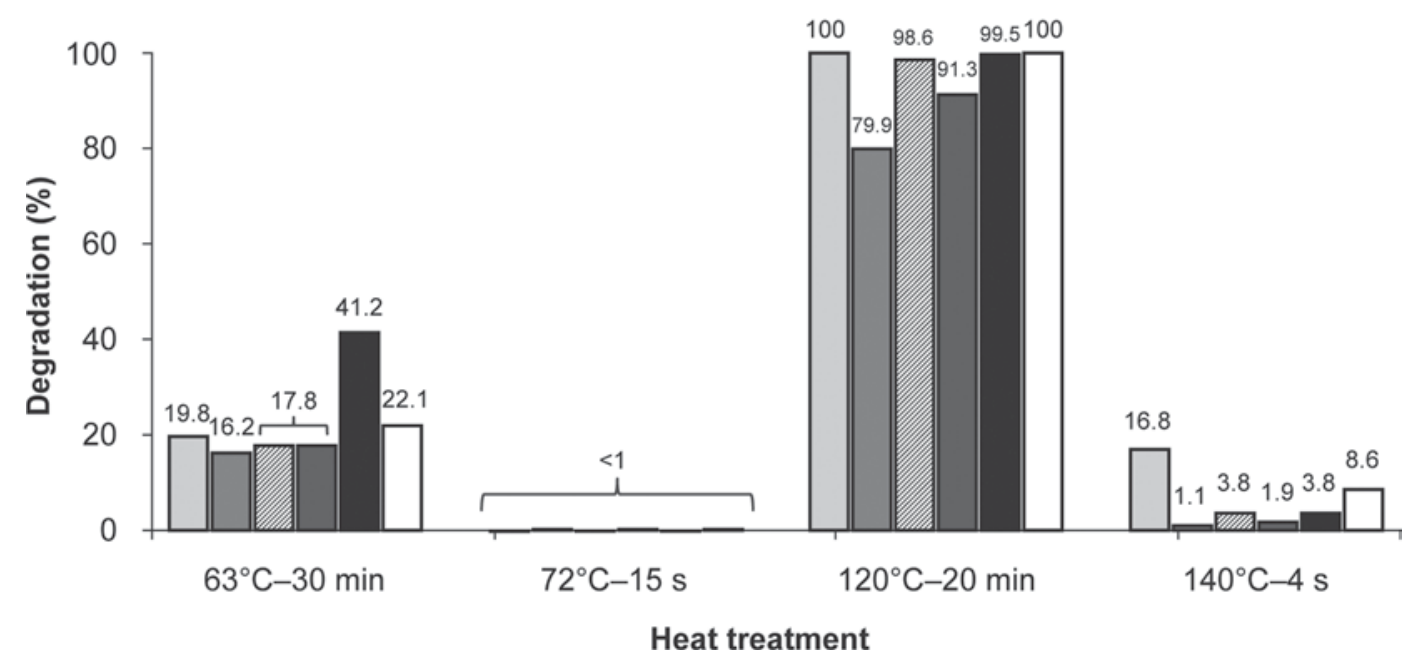

Figure 4. Degradation percentages of cephalosporins in milk with different heat treatments.

assay containing spores of Geobacillus stearothermophilus. These authors obtained higher inactivation values for penicillins ( $65 \%$ penicillin G, $72 \%$ cloxacillin, and $88 \%$ amoxicillin), and similar values for cephalosporins (>90\%) than those found in this work for sterilization at $120^{\circ} \mathrm{C}$ for $20 \mathrm{~min}$.

For pasteurization at $63^{\circ} \mathrm{C}$ for $30 \mathrm{~min}$, Zorraquino et al. (2008) achieved low antimicrobial activity loss for penicillins (between $7 \%$ for cloxacillin and $11 \%$ for amoxicillin) and cephalosporins (between $6 \%$ for cefquinome and $18 \%$ for cefoperazone), which are similar to the values reported in Figure 4.

It should also be noted that Zorraquino et al. (2008) used a microbiological method to determine antimicrobial activity losses, whereas the present work uses chromatographic methods to calculate concentration losses of $\beta$-lactams due to changes or degradation in the original molecules.

In the literature review, we did not find studies analyzing the thermostability of $\beta$-lactam antibiotics in milk using chromatographic techniques (HPLC) or reports of predictive models to estimate the thermal degradation of these antibiotics in milk.

\section{CONCLUSIONS}

By applying a first-order kinetic model and the Arrhenius equation, it is possible to develop predictive models to explain the thermal degradation of $\beta$-lactam antibiotic residues in milk. The degradation half-lives of these antibiotics decrease with increasing temperatures. Cephalosporins present shorter half-lives and greater instability to heat than do penicillins. The use of predictive models helps in the estimation of thermal degradation of each $\beta$-lactam antibiotic for the different processes applied in the dairy industry. The milk processing techniques cited herein cause minor losses in the concentration of $\beta$-lactam antibiotics, except for milk sterilization at $120^{\circ} \mathrm{C}$ for $20 \mathrm{~min}$, which implies that most heat treatments do not prevent these antimicrobial substances from reaching consumers. Therefore, it is necessary to correctly implement preventive and control measures throughout the milk production chain to avoid potential risks from the food safety viewpoint.

\section{ACKNOWLEDGMENTS}

This work is part of the AGL2003-03663 project financed by the Spanish Ministry of Education and Science (Madrid, Spain) and the Vice-Rectorate for Research, Development and Innovation of the Polytechnic University of Valencia (UPV), Spain. The authors thank the UPV for funding the collaboration of Rafael Althaus.

\section{REFERENCES}

Akaho, E., and H. Nakayama. 2003. An innovative classification of, and a new structure-activity-relationship approach to degradation kinetics of cephalosporins: an attempt to enhance the therapeutic activity. J. Antibiot. (Tokyo) 56:379-391.

Alekseev, V. G., S. V. Larin, O. Y. Shigina, and E. E. Shcherbakova. 2006. Interaction of ampicillin with zinc and cadmium ions in aqueous solutions. Russ. J. Gen. Chem. 76:317-320.

Ash, I., and M. Ash. 1995. Handbook of Pharmaceutical Additives. Gower Technical, Hampshire, UK.

Botsoglou, N. A., and J. D. Fletouris. 2001. Drug Residues in Foods: Pharmacology, Food Safety, and Analysis. Food Science and Technology. Marcel Dekker, New York, NY. 
Bradley, A. J., and M. D. Green. 2009. Factors affecting cure when treating bovine clinical mastitis with cephalosporin-based intramammary preparations. J. Dairy Sci. 92:1941-1953.

Carstensen, J. T., and C. Rhodes. 2000. Drug Stability: Principles and Practices. Marcel Dekker Inc., New York, NY.

Chen, J. J., H. Ahn, and Y. Tsong. 1997. Shelf-life estimation for multifactor stability studies. Drug Inf. J. 31:573-587.

Cimarusti, C. M. 1984. Dependence of beta-lactamase stability on substructures within beta-lactam antibiotics. J. Med. Chem. $27: 247-253$.

Codex Alimentarius. 2009. Maximum Residue Limits for Veterinary Drugs in Foods Updated as at the 32nd Session of the Codex Alimentarius Commission. Codex Alimentarius Commission, Rome, Italy.

Cohen, N. C. 1983. $\beta$-Lactam antibiotics: Geometrical requirements for antibacterial activities. Med. Chem. 26:259-264.

Connors, K. A., V. J. Stella, and G. L. Amidon. 1994. Chemical Stability of Pharmaceuticals. John Wiley \& Sons, New York, NY.

European Council. 2010. Council Regulation 37/2010 of the European Communities. Pharmacologically active substances and their classification regarding maximum residue limits in foodstuffs of animal origin. Off. J. L15:1-72.

Demoly, P., and A. Romano. 2005. Update on beta-lactam allergy diagnosis. Curr. Allergy Asthma Rep. 5:9-14.

Deshpande, A. D., K. G. Baheti, and N. R. Chatterjee. 2004. Degradation of $\beta$-lactam antibiotics. Curr. Sci. 87:1684-1694.

Ghidini, S., E. Zanardi, G. Varisco, and R. Chizzolini. 2003. Residues of beta-lactam antibiotics in bovine milk: Confirmatory analysis by liquid chromatography tandem mass spectrometry after microbial assay screening. Food Addit. Contam. 20:528-534.

Guillemot, D., C. Carbon, B. Balkau, P. Geslin, H. Lecoeur, F Vauzelle-Kervroedan, G. Bouvenot, and E. Eschwege. 1998. Low dosage and long treatment duration of $\beta$-lactam. Risk factors for carriage of penicillin-resistant Streptococcus pneumoniae. JAMA 279:365-370

Holstege, D. M., B. Puschner, G. Whitehead, and F. D. Galey. 2002 Screening and mass spectral confirmation of $\beta$-lactam antibiotic residues in milk using liquid chromatography-MS/MS. J. Agric. Food Chem. 50:406-411.

Honkanen-Buzalski, T., and W. Reybroeck. 1997. Antimicrobials. Pages 26-34 in Residues and Contaminants in Milk and Milk Products. IDF S.I. no. 9701. International Dairy Federation, Brussels, Belgium.

ISO. 2005. General requirements for the competence of testing and calibration laboratories. ISO/IEC 17025:2005. AENOR, Madrid, Spain.

Martin, A. 1993. Pages 297-298 in Physical Pharmacy: Physical Chemical Principles in the Pharmaceutical Sciences. 4th ed. Lea and Febiger, Philadelphia, PA.

Michnik, A., K. Michalik, and W. Marcoin. 2004. Influence of magnesium glutamate on stability of penicillin $\mathrm{G}$ aqueous solution. Int. J. Pharm. 273:149-158.
Miller, J. M., U. J. Kale, S. K. Lau, L. Greene, and H. Y. Hang. 2004 Rapid estimation of kinetic parameters for thermal decomposition of penicillins by modulated thermogravimetric analysis. J. Pharm. Biomed. Anal. 35:65-73.

Moats, W. A. 1988. Inactivation of antibiotics by heating in foods and other substrates: A review. J. Food Prot. 51:491-497.

Moats, W. A. 1999. The effect of processing on veterinary residues in foods. Pages 233-241 in Impact of Processing on Food Safety. Kluwer Academic, Plenum Publishers, New York, NY.

Moats, W. A., and R. Harik-Khan. 1995. Liquid chromatographic determination of $\beta$-lactam antibiotics in milk: A multiresidue approach. J. AOAC Int. 78:49-54.

Moats, W. A., and R. Malisch. 1992. Determiantion of cloxacillin and penicillin $\mathrm{V}$ in milk using an automated liquid chromatography cleanup. J. AOAC Int. 75:257-260.

Navarro, P. G.. I. H. Blázquez, B. Q. Osso, P. J. Martinez de las Parras, M. I. Puentedura, and A. A. García. 2003. Penicillin degradation catalysed by $\mathrm{Zn}^{2+}$ ions in methanol. Int. Biol. Macromol. 4-5:159-166.

Packham, W. M. C. Broome, G. K. Y. Limsowtin, and H. Roginski. 2001. Limitations of standard antibiotic screening assays when applied to milk for cheesemaking. Aust. J. Dairy Technol. 56:1518.

Pawelczyk, E., Z. Plotkowiak, K. Knitter, and B. Kozakiewiczwegner. 1980. Kinetic of drug decomposition. Kinetics of penicillin G potassium salt (PGP) thermal degradation in solid phase. Pol. J. Pharmacol. Pharm. 32:55-62.

Pengov, A. 2009. Risks of antibiotic residues in milk following intramammary and intramuscular treatments in dairy sheep. Anal. Chim. Acta 637:13-17.

Roca, M., M. Castillo, P. Marti, R. L. Althaus, and M. P. Molina 2010. Effect of heating on the stability of quinolones in milk. J Agric. Food Chem. 58:5427-5431.

Rodante, F., S. Vecchio, and M. Tomassetti. 2002. Multi-step decomposition processes for some antibiotics. A kinetic study. Thermochim. Acta 394:7-18.

SAS Institute. 2001. SAS User's Guide: Statistics. Version 9.1. SAS Institute Inc., Cary, NC.

Tarbin, J. A., H. Farrington, and G. Shearer. 1995. Determination of penicillins in animal tissues at trace residue concentrations. Part I. Determination of benzylpenicillin in milk by reversed-phase liquid chromatography with solid phase extraction and liquid chromatographic fractionation clean-up. Anal. Chim. Acta 318:95-101.

Wilke, M., A. L. Lovering, and N. Strynadka. 2005. $\beta$-Lactam antibiotic resistance: A current structural perspective. Curr. Opin. Microbiol. 8:525-533.

Zajac, M., J. Siwek, and I. Muszalska. 1998. The mechanism of ceftazidime degradation in aqueous solutions. Acta Pol. Pharm. $55: 275-278$.

Zorraquino, M. A., M. Roca, N. Fernández, M. P. Molina, and R. L. Althaus. 2008. Heat inactivation of beta-lactam antibiotics in milk. J. Food Prot. 71:1193-1198. 